\title{
Analysis of Causal Relationship between Supply Chain Security and Its Performance Using Balanced Scorecard Model
}

\author{
Ji-Young Park*, Jung Ung Min**, and Jeong Soo Park***
}

\begin{abstract}
Though logistics security only took care of trading phase in the past, many countries in the world have begun to introduce logistics security system as its coverage has been extended from production stage to delivery at the final destination. Logistics security system has become indispensable element for global corporations involved in international trading and studies on logistics security keep going on. Most of the studies, however, are focused on discussion of system, cost and influence of logistics security and few of them have been specifically dealing with substantial effectiveness thereof. This study developed the models of supply chain security activities and their outcome by means of using Balanced Scorecard (BCS) which is a well known performance indicator to identify relationship between supply chain security activities and their accomplishment. In this study we have presented 8 supply chain frameworks, human resources management, information system management, facilities/freight management, security process, crisis management capability, relationship with partners, sharing of logistics information and logistics security accomplishment, with reference to standards of C-TPAT and AEO based on WCO framework, 10 supply chain security capabilities. This study further indicates that relationship with partners has more effect on logistics security accomplishment than sharing of logistic information. Just as relationship between corporations in chain of supply and sharing of information among them are important elements in management of supply chain, relationship with partners and sharing of logistic information will have positive effect on supply chain security accomplishment and raise its effectiveness.
\end{abstract}

Keyword : Supply Chain Security, Logistics Security, Structural Equation Model, SEM, Balanced Scorecard, BSC

Submission Date: 10/15/2011 Revision Date: 10/28/2011 Acceptance Date: 10/28/2011

* Graduate Student, Graduate School of Logistics, Inha University, E-mail: garnet6953@naver.com

** Corresponding Author, Associate Professor, Asia-Pacific School of Logistics, Inha University, E-mail: jumin@inha.ac.kr

*** Ph. D Student, Graduate School of Logistics, Inha University, E-mail: jspark@samjincore.co.kr 


\section{Introduction}

Ever since we have 9.11 Attack in 2011, global enterprises have suffered a severe confusion in its production lines. Those corporations which employed just-in-time inventory strategy suffered stoppage of production due to the incident. This turmoil cleary showed that global enterprises procuring their parts from other countries and selling finished products to elsewhere suffered secondary damages which led corporations to lay stress on security from the perspective of supply chain. Though logistics security only took care of trading phase in the past, many countries in the world have begun to introduce logistics security system as its coverage has been extended from production stage to delivery at the final destination. Logistics security system has become indispensable element for global corporations involved in international trading and studies on logistics security keep going on. Most of the studies, however, are focused on discussion of system, cost and influence of logistics security and few of them have been specifically dealing with substantial effectiveness there of.

In this regard, this study developed models of supply chain security activities and their outcome by means of using BSC which is a well known performance indicator to identify relationship between supply chain security activities and their accomplishment. The study aimed to take a grip of causal relationship between supply chain security activities and their accomplishment by utilizing a model of structural equation and validate it. To accomplish the purpose of research, this study has relied on both literary investigation and empirical analysis. Based on existing studies, theoretical and measured variables have been set up in a way which can demonstrate activities of supply chain security. Also, theoretical and measured variables in respect of supply chain security accomplishment have been extracted, in order to present research model and hypothesis. In empirical analysis, data collected from local corporations polled have been utilized by means of structural equation to validate relevance of research model and research hypothesis.

Since 9.11 Attack, United States has been intensifying security regulations to ensure safety of not only cargos coming in through air and sea ports but also identity of transportation workers. As global logistics industry is suffering from intensified logistics regulations, a lot of studies on logistics security are being carried out as shown in Table 1. Review of the existing studies indicates that there are a relatively small number of researches on accomplishment of supply chain security compared to those on supply chain security system. Existing theses on accomplishment of supply chain logistics security simply provide an array of advantages gained from supply chain security and its cost. It was difficult to find out theses discussing causal relationship between supply chain security measures and supply chain security accomplishment as most of them have been undertaken only through measuring level of corporate supply chain security. 
Table 1.

Literature review on logistics security

\begin{tabular}{|c|c|c|c|c|}
\hline \multirow{2}{*}{ Research } & \multirow{2}{*}{$\begin{array}{l}\text { Security } \\
\text { Policy }\end{array}$} & \multirow{2}{*}{$\begin{array}{c}\text { Security } \\
\text { Technology }\end{array}$} & \multicolumn{2}{|c|}{ Impact on Supply Chain } \\
\hline & & & Cost & Performance \\
\hline $\begin{array}{l}\text { C. C. White III, A. L. Erera, and } \\
\text { MWP Savelbergh (2004) }\end{array}$ & $\sqrt{ }$ & & & \\
\hline P Barnes and R Oloruntoba (2005) & $\sqrt{ }$ & & & \\
\hline $\begin{array}{l}\text { A Erera, KH Kwek, N Goswami, } \\
\text { C White, and H Zhang (2003) }\end{array}$ & $\sqrt{ }$ & & $\sqrt{ }$ & \\
\hline $\begin{array}{l}\text { David Closs, O. Keith Helferich, } \\
\text { Daniel Lynch, Robyn Mace, } \\
\text { Ed McGarrell, Cheri Speier, } \\
\text { Judy Whipple, and Doug Voss (2008) }\end{array}$ & & & & $\sqrt{ }$ \\
\hline $\begin{array}{c}\text { Susan E. Martonosi, David S. Ortiz, and } \\
\text { Henry H. Wills }\end{array}$ & $\sqrt{ }$ & $\sqrt{ }$ & $\sqrt{ }$ & \\
\hline R Banomyong (2005) & $\sqrt{ }$ & & $\sqrt{ }$ & \\
\hline JA Roach (2004) & $\sqrt{ }$ & & & \\
\hline $\begin{array}{l}\text { Barchi Peleg-Gillai, Gauri Bhat, and } \\
\text { Leslet SeptBarchi (2006) }\end{array}$ & & & & $\sqrt{ }$ \\
\hline James B. Rice, Jr. (2005) & & & & $\sqrt{ }$ \\
\hline Y. Sheffi (2003) & $\sqrt{ }$ & & & \\
\hline
\end{tabular}

\section{Research methodology}

In this study, balanced scorecard being one of performance measurement techniques has been used to disclose causal relationship between supply chain security measures and supply chain security accomplishment. BSC is a method of performance measurement and was developed by Kaplan and Norton in 1992 whereby management decision making process can be upgraded by consolidating organizational performance indicators with strategic plans and objectives. BSC is a method of performance measurement designed to 
make up for previous performance indicator depending too much on financial measurement indicators. Lee Sang Hyeon (2003) stated that it was a strategic technique for performance evaluation and value measurement whereby corporate performance is measured by having financial as well as non-financial measurement indicators considered together and also current and future value of a corporation is evaluated. Kaplan and Norton (1992) defined $\mathrm{BSC}$ to be a set of performance measures which can help chief executive officers measure business results rapidly and from an integrated point of view.

$\mathrm{BSC}$ is a measurement indicator for driving force which creates future performance and uses complimentarily non-financial indicators in addition to financial ones. Starting from long term financial objectives, BSC lets a corporation achieve its objectives by linking 4 perspectives of learning and growth perspective, internal business process perspective, customer perspective and financial perspective for desirable performance. Among such 4 perspectives of BSC, learning and growth perspective has influence on internal business process perspective which, in turn, affects customer perspective which has effect on financial perspective thereby forming causal relationship among them.

In this study, BSC causal relationship diagram has been drawn out through advance study to analyze relationship between supply chain security activities and supply chain security accomplishment by means of utilizing 4 perspectives of learning and growth, internal business process, customer and finance. BSC causal relationship diagram means a conceptual tool visually showing integrated strategic objectives of an organization from such 4 perspectives of BSC. Causal relationship between perspectives can be examined through such BSC causal relationship diagram.

\section{Research model}

This study has presented 8 supply chain frameworks, human resources management, information system management, facilities/freight management, security process, crisis management capability, relationship with partners, sharing of logistics information and logistics security accomplishment (7 supply chain security activities and 1 supply chain security accomplishment), with reference to standards of C-TPAT and AEO based on WCO framework, 10 supply chain security capabilities studied by Closs et. al. (2008) and 6 supply chain security as classified by Hintas (2005). Due to lack of prior studies on supply chain security accomplishment, new BSC logistics security model has been proposed on the basis of the results of existing research on logistics strategy by means of building BSC (Min Gyeong Gi, 2005) and 8 supply chain frameworks drawn out in the foregoing. 
Min Gyeong Gi (2005) came up with CSF and KPI by means of classifying prior studies on existing logistics strategies into categories of integration, innovation and responsiveness. Further, he drew out measurement indicator for logistics performance through prior studies on logistics accomplishment. Out of CSF and KPI made available from prior studies, learning and growth perspective (integration) has been classified into rebuilding of organizational structure and utilization of information technology, internal business process perspective (innovation) into innovation of process, customer perspective (responsiveness) into utilization of outsourcing and sharing of logistics information and financial perspective into uplifting of logistics accomplishment. In this study based on the research results of Min Gyeong Gi (2005), 6 supply chain security management frameworks classified by Hintas (2005) from the perspective of supply chain security, major security standards sorted out by C-TPAT, AEO and 10 supply chain security capabilities divided by Closs et. al. (2008) have been classified according to 4 BSC perspectives. Learning and growth perspective has been grouped with human resources and information system management, internal business perspective with facilities/freight management, security process, crisis management capability, customer perspective with partnership and sharing of logistic information and financial perspective with logistics security accomplishment. This has been summarized in Table 2 .

\section{Table 2.}

Classification of supply chain security based on BSC

\begin{tabular}{|c|c|c|}
\hline $\mathrm{BSC}$ & $\begin{array}{l}\text { Logistics Strategy } \\
\text { By Min (2005) }\end{array}$ & Supply Chain Security Classification \\
\hline \multirow{2}{*}{ Learning and Growth } & $\begin{array}{l}\text { Rebuilding organizational } \\
\text { structure }\end{array}$ & Human resources \\
\hline & $\begin{array}{l}\text { Utilization of information } \\
\text { technology }\end{array}$ & Information system management \\
\hline \multirow{3}{*}{ Internal business process } & \multirow{3}{*}{ Innovation of process } & Facilities/freight management \\
\hline & & Security process \\
\hline & & Crisis management capability \\
\hline \multirow{2}{*}{ Customer } & Outsourcing & Partnership \\
\hline & Sharing logistics information & Sharing of logistic information \\
\hline Financial & $\begin{array}{l}\text { Uplifting of logistics } \\
\text { accomplishment }\end{array}$ & Logistics security accomplishment \\
\hline
\end{tabular}


Causal relationship diagram of this study is shown in Figure 1. Efficiency of facilities/freight management, security process and crisis management capability can become different depending on human resources and information system management which is a logistics security activity from the learning and growth perspective of BSC and can allow stable system and process to be built. In addition, corporate capabilities for facilities/freight management, security process and crisis management capability can have influence on partner relationship and sharing of information which, in turn, forms a basis for obtaining results in logistics security. Research model based on BSC is premised that BSC characteristics have causal relationship. This study attempted to validate extent of causal relationship by setting up BSC causal relationship diagram in a structural equation model. In this study, company-wide BSC logistics security activities established on the basis of prior studies have been illustrated in BSC causal relationship diagram.

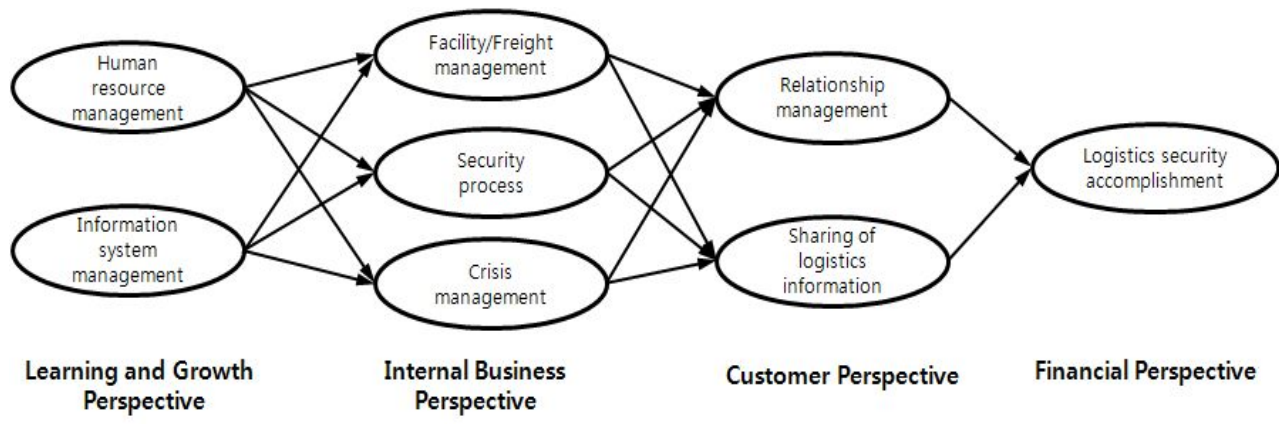

Figure 1.

BSC causal relationship diagram

Based on prior studies on logistics security, this study has set up the following hypothesis on the ground of the research model shown in the Table 3. To fulfill the purpose of research on the relationship between supply chain security activities and supply chain security accomplishment, variables of logistics security have been defined on the basis of mandatory conditions as regulated by the existing international logistics security system.

\subsection{Human Resources Management (HRM)}

In this study, human resources management has been measured based on Likert 5 points scale as to whether instruction and training have been provided to staff members for the purpose of preventing, recognizing, detecting and coping with logistics security incidents. 


\subsection{Information System Management (ISM)}

In this study, information system management has been measured based on Likert 5 points scale as to whether they are capable of tracing products moving to and from customers and suppliers and level of security process.

\subsection{Facilities/freight management (F/FM)}

In this study, facilities/freight management has been measured based on Likert 5 points scale as to whether entry-exit of staffs and visitors is controlled for the sake of facilities and logistics security and whether there are established procedures to take delivery of freight at in-house facilities.

\subsection{Security process (SP)}

In this study, security process has been measured based on Likert 5 points scale as to whether logistics security guidelines as recommended by the government have been accommodated and whether there is a process whereby logistics security incidents can be prevented, detected, recognized, coped with and made good.

\subsection{Crisis management (CM)}

In this study, crisis management has been measured based on Likert 5 points scale as to whether they are participating in contingency plans in cooperation with pertinent government agencies, whether they are preparing for logistics security incidents in conjunction with pertinent authorities, whether they are participating in emergency response exercise and whether they have contingency and recovery plans in place.

\subsection{Relationship Management (RM)}

In this study, relationship with partners has been measured based on Likert 5 points scale as to whether they provide vendors and clients with training program for logistics security procedures, whether their service providers comply with international logistics security guidelines, whether service providers have logistics security enhancement programs, how their suppliers are doing in case where proper logistics security procedures are not available and whether feed back on the results of logistics security audit properly works. 


\subsection{Sharing of logistics information (SLI)}

In this study, sharing of logistics information has been measured based on Likert 5 points scale as to whether they file a report with government upon occurrence of a logistics security incident, whether relevant information is properly shared by all staff members in case of a logistics security incident and whether pertinent information is provided to government or the general public in the event of occurrence of a logistics security incident.

\subsection{Logistics security accomplishment (LSA)}

In this study, logistics security accomplishment has been measured based on Likert 5 points scale as to how often theft of or damage to freight occurs, how client companies evaluate their image and reliability in respect of logistics security and what the details of cost incurred in case of logistics security incident as a result of lack of communication is.

Table 3.

Research Hypothesis

\begin{tabular}{|c|c|}
\hline & Content \\
\hline H1 & HRM have plus $(+)$ effect on F/FM \\
\hline H2 & HRM have plus $(+)$ effect on SP \\
\hline H3 & HRM have plus $(+)$ effect on CM \\
\hline H4 & ISM have plus $(+)$ effect on F/FM \\
\hline H5 & ISM have plus $(+)$ effect on SP \\
\hline H6 & ISM have plus $(+)$ effect on CM \\
\hline H7 & F/FM have plus $(+)$ effect on RM \\
\hline H8 & F/FM have plus $(+)$ effect on SIM \\
\hline H9 & CM have plus $(+)$ effect on RM \\
\hline H10 & CM have plus $(+)$ effect on SIM \\
\hline H11 & SP have plus $(+)$ effect on RM \\
\hline H12 & SP have plus $(+)$ effect on SIM \\
\hline H13 & RM have plus $(+)$ effect on LSA \\
\hline H14 & SIM have plus $(+)$ effect on LSA \\
\hline
\end{tabular}




\section{Result of analysis}

\subsection{Reliability test}

Reliability means the extent of consistence in multivariate variables as measured which are meant to signify distribution of values obtained as a result of repeated measurement of the same concept. In this study, measurement has been done using Cronbach's alpha coefficient which can evaluate reliability of individual items comprising the applicable measure. Though there are no uniform criteria applicable to Cronbach's alpha reliability measurement, it is generally known that $0.5 \sim 0.6$ will be sufficient. This study accordingly conducted validation of reliability with Cronbach's alpha coefficient placed above 0.7 .

The result of reliability analysis showed higher than 0.7 in Cronbach's alpha value indicating that it is reliable. Cronbach's alpha value against 3 questionnaires regarding human resources management turned out to be 0.925 indicating very high reliability while that of 2 questionnaires in respect of information system management to be 0.700 indicating acceptable level of reliability. Cronbach's alpha value against 2 questionnaires concerning facilities/freight management came out to be 0.817 showing reliability. Cronbach's alpha value against 4 questionnaires regarding security process turned out to be 0.920 indicating very high reliability and that covering 3 questionnaires dealing with crisis management capability to be 0.912 suggesting relatively high level of reliability. Cronbach's alpha value against 5 questionnaires regarding relationship with partners turned up to be 0.843 indicating high reliability and that against 3 questionnaires concerning sharing of logistic information showed up to be 0.843 revealing high reliability. Lastly, Cronbach's alpha value against 2 questionnaires in respect of logistics security accomplishment came out to be 0.749 suggesting satisfactory level of reliability.

\subsection{Validity test}

While reliability deals mainly with consistence, validity is a notion showing up whether certain concepts or properties have been accurately measured. Validity is to do with whether measurement tools developed to measure concepts or properties accurately reflect applicable characteristics. As the hypothesis of this study has been set up on the basis of existing researches, this study only conducted confirmatory factor analysis omitting exploratory factor analysis which is used for exploratory understanding of basic structure in 
the area where theoretical structure has not been set up firmly in place. When it comes to confirmatory factor analysis, comparative fit index (CFI: $0.9>=$ or above is desirable) and root mean square error of approximation (RMSEA: $0.05<$ or below is desirable) etc. have been used.

As a result of confirmatory factor analysis, it turned up to be $\mathrm{X}^{2}=386.974, \mathrm{df}=224$ and $\mathrm{p}=0.000$ with comparative fit index (CFI: 0.915), Tucker-Lewis Index (TLI: 0.896) and root mean square error of approximation (RMSEA: 0.083). Although TLI and RMSEA values failed to reach the recommended level, it appears to be a valid model as the values stay at permissible level. The result of confirmatory factor analysis is in Table 4. As the result of confirmatory factor analysis showed up construct reliability higher than 0.7 and average variance extracted higher than 0.5 exceeding threshold, we can say that reliability and convergence validity have been secured. 
Table 4.

Confirmatory Factor Analysis

\begin{tabular}{|c|c|c|c|c|c|c|}
\hline $\begin{array}{l}\text { Structure } \\
\text { variable }\end{array}$ & $\begin{array}{l}\text { Measurement } \\
\text { variable }\end{array}$ & Estimate & Error term & Critical Ratio & $\begin{array}{l}\text { Construct } \\
\text { Reliability }\end{array}$ & $\begin{array}{l}\text { Average } \\
\text { Variance } \\
\text { Extracted }\end{array}$ \\
\hline \multirow{3}{*}{ HRM } & Q1 & 0.904 & 0.167 & 12.666 & \multirow{3}{*}{0.935} & \multirow{3}{*}{0.910} \\
\hline & Q2 & 0.926 & 0.117 & 13.342 & & \\
\hline & Q3 & 0.863 & 0.22 & & & \\
\hline \multirow{2}{*}{ ISM } & Q4 & 0.618 & 0.378 & & \multirow{2}{*}{0.806} & \multirow{2}{*}{0.825} \\
\hline & Q5 & 0.870 & 0.155 & 5.565 & & \\
\hline \multirow{2}{*}{$\mathrm{F} / \mathrm{FM}$} & Q6 & 0.846 & 0.205 & 7.506 & \multirow{2}{*}{0.872} & \multirow{2}{*}{0.879} \\
\hline & Q7 & 0.819 & 0.203 & & & \\
\hline \multirow{4}{*}{ SP } & Q8 & 0.786 & 0.349 & & \multirow{4}{*}{0.930} & \multirow{4}{*}{0.877} \\
\hline & Q9 & 0.887 & 0.215 & 10.424 & & \\
\hline & Q10 & 0.925 & 0.123 & 10.863 & & \\
\hline & Q11 & 0.865 & 0.216 & 10.068 & & \\
\hline \multirow{3}{*}{$\mathrm{CM}$} & Q12 & 0.922 & 0.183 & 10.752 & \multirow{3}{*}{0.906} & \multirow{3}{*}{0.874} \\
\hline & Q13 & 0.965 & 0.083 & 11.319 & & \\
\hline & Q14 & 0.771 & 0.371 & & & \\
\hline \multirow{5}{*}{$\mathrm{RM}$} & Q15 & 0.737 & 0.431 & & \multirow{5}{*}{0.885} & \multirow{5}{*}{0.780} \\
\hline & Q16 & 0.846 & 0.252 & 8.599 & & \\
\hline & Q17 & 0.841 & 0.271 & 8.599 & & \\
\hline & Q18 & 0.667 & 0.481 & 6.800 & & \\
\hline & Q19 & 0.699 & 0.429 & 7.004 & & \\
\hline \multirow{3}{*}{ SLM } & Q20 & 0.803 & 0.405 & 10.060 & \multirow{3}{*}{0.856} & \multirow{3}{*}{0.816} \\
\hline & Q21 & 0.734 & 0.409 & 8.184 & & \\
\hline & Q22 & 0.888 & 0.175 & & & \\
\hline \multirow{2}{*}{ LSA } & Q23 & 0.722 & 0.336 & & \multirow{2}{*}{0.814} & \multirow{2}{*}{0.829} \\
\hline & Q24 & 0.829 & 0.213 & 6.258 & & \\
\hline
\end{tabular}

Discriminate validity indicates a case where there are very low correlations among values resulting from measurement of a concept contained in the group of differing concepts. Examination of discriminate validity indicates it has been satisfied as correlation 
coefficient and multiple value of correlation turned up to be lower than average variance extracted. The result of discriminant validity has been summarized in Table 5 .

Table 5.

Discriminant validity

\begin{tabular}{|c|c|c|c|c|c|c|c|c|}
\hline & LSA & SIM & RM & CM & SP & F/FM & ISM & HRM \\
\hline LSA & $0.829^{*}$ & & & & & & & \\
\hline SIM & 0.566 & $0.816^{*}$ & & & & & & \\
\hline RM & 0.578 & 0.690 & $0.780^{*}$ & & & & & \\
\hline CM & 0.427 & 0.753 & 0.746 & $0.874^{*}$ & & & & \\
\hline SP & 0.630 & 0.670 & 0.768 & 0.694 & $0.877^{*}$ & & & \\
\hline F/FM & 0.582 & 0.367 & 0.395 & 0.326 & 0.57 & $0.879^{*}$ & & \\
\hline ISM & 0.672 & 0.553 & 0.599 & 0.536 & 0.702 & 0.630 & $0.825^{*}$ & \\
\hline HRM & 0.487 & 0.382 & 0.483 & 0.489 & 0.55 & 0.635 & 0.55 & $0.910^{*}$ \\
\hline
\end{tabular}

\subsection{Structure Equation Modeling analysis}

Structure equation modeling (SEM) is a multivariate analysis technique being a statistical analysis method mainly used for validation of hypothesis. Structure equation modeling (SEM) refers to an equation model used to understand causal relationship between models through measurement model and structure model. This can be said to be an improvement combining confirmatory factor analysis which finds out potential factors free of measurement error and regression analysis connecting potential factors.

This study carried out structure equation modeling analysis using AMOS 7.0 program. Intial SEM model and results have been presented in Figure 2 and Table 6. For validation of the research model, following structure equation model has been prepared on the basis of the research model validated through reliability and validity analysis. As a result of confirmatory factor analysis, it turned up to be $\mathrm{X}^{2}=458.661, \mathrm{df}=238$ and $\mathrm{p}=0.000$ with root mean square error of approximation (RMSEA: 0.094) and comparative fit index (CFI: 0.885), Tucker-Lewis Index (TLI: 0.867) showing acceptable level of relevance suggesting the research model has significance. 


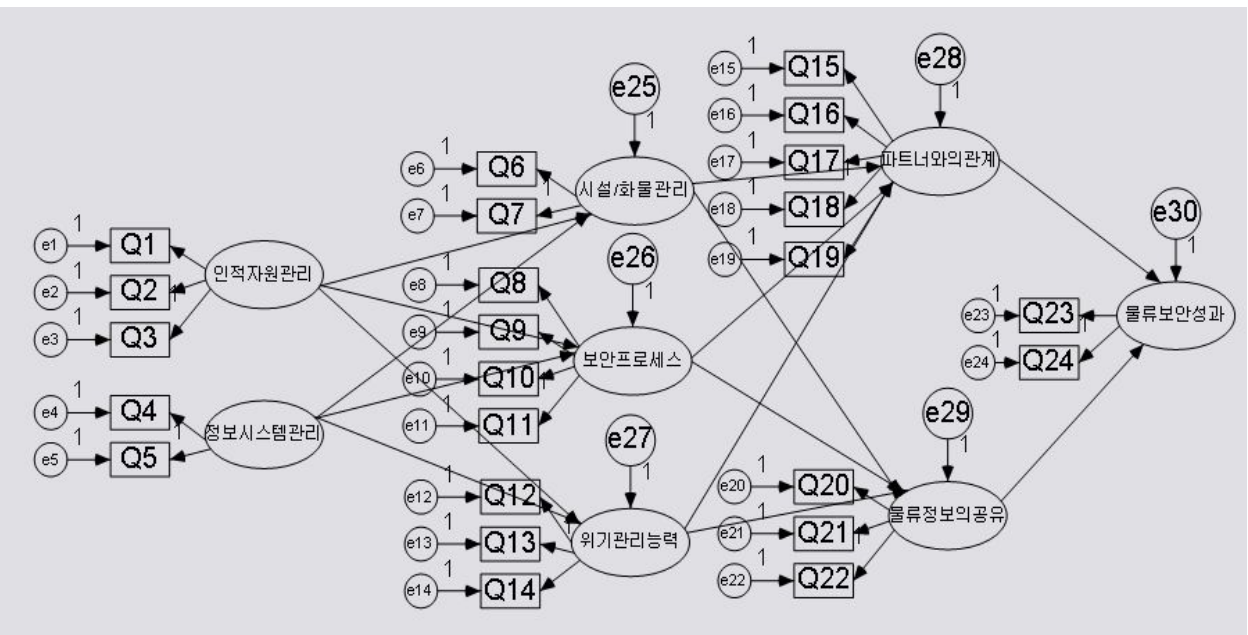

Figure 2.

Structure Equation Modeling for BSC based supply chain security

Table 6.

SEM analysis result

\begin{tabular}{|c|c|c|c|c|}
\hline & Estimate & S.E. & C.R. & P \\
\hline F/FM $\leftarrow$ HRM & 0.497 & 0.08 & 4.447 & 0.000 \\
\hline SP $\leftarrow$ HRM & 0.301 & 0.078 & 3.623 & 0.000 \\
\hline $\mathbf{C M} \leftarrow$ HRM & 0.297 & 0.112 & 3.3 & 0.000 \\
\hline F/FM $\leftarrow$ ISM & 0.431 & 0.112 & 3.599 & 0.000 \\
\hline $\mathbf{S P} \leftarrow \mathbf{I S M}$ & 0.747 & 0.155 & 5.872 & 0.000 \\
\hline $\mathbf{C M} \leftarrow \mathbf{I S M}$ & 0.556 & 0.18 & 5.001 & 0.000 \\
\hline RM $\leftarrow$ F/FM & -0.015 & 0.093 & -0.159 & 0.874 \\
\hline $\mathbf{S I M} \leftarrow \mathbf{F} / \mathbf{F M}$ & 0.025 & 0.133 & 0.242 & 0.808 \\
\hline $\mathbf{R M} \leftarrow \mathbf{S P}$ & 0.511 & 0.089 & 4.353 & 0.000 \\
\hline $\mathbf{S I M} \leftarrow \mathbf{S P}$ & 0.296 & 0.106 & 2.825 & 0.005 \\
\hline $\mathbf{R M} \leftarrow \mathbf{C M}$ & 0.417 & 0.059 & 4.05 & 0.000 \\
\hline $\mathbf{S I M} \leftarrow \mathbf{C M}$ & 0.549 & 0.076 & 5.455 & 0.000 \\
\hline $\mathbf{L S A} \leftarrow \mathbf{R M}$ & 0.353 & 0.174 & 2.5 & 0.012 \\
\hline $\mathbf{L S A} \leftarrow \mathbf{S I M}$ & 0.3 & 0.128 & 2.185 & 0.029 \\
\hline
\end{tabular}


In this study, parametric estimation has been made using AMOS 7.0. As indicated in the following table, all hypotheses except for the one that "facilities/freight management will have plus (+) effect on relationship with partners and sharing of logistics information" showed significance level lower than 0.05 indicating they are statistically relevant and can be, therefore, adopted. This means that facilities/freight management does not have direct effect on relationship with partners and sharing of logistics information. Although facilities/freight management does not have direct effect on relationship with partners and sharing of logistics information, we modified research path and re-measured research model as it can have direct effect on logistics security accomplishment.

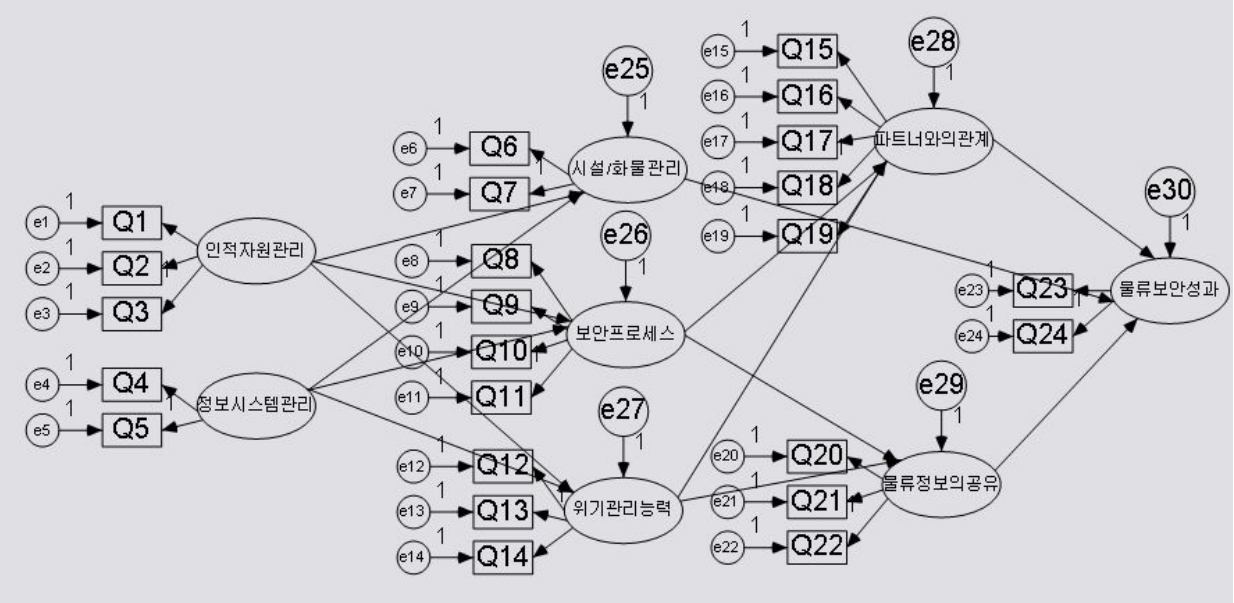

Figure 3.

Revised SEM model

As shown in Figure 3., in case where facilities/freight management has direct effect on logistics security accomplishment, it turned up to be $X^{2}=446.110, \mathrm{df}=239$ and $\mathrm{p}=0.000$ with root mean square error of approximation (RMSEA: 0.090) and comparative fit index (CFI: 0.892), Tucker-Lewis Index (TLI: 0.876) indicating acceptable level of relevance. The hypothesis that "relationship management and sharing of logistics information have plus $(+)$ effect on logistics security accomplishment" showed significance level lower than 0.1 indicating they are statistically relevant while the rest of hypotheses turned out to be statistically relevant with significance level of 0.05 . Revised result is in Table 7 . 
Table 7.

Revised result

\begin{tabular}{|c|r|r|r|r|}
\hline Hypothesis & \multicolumn{1}{|c|}{ Estimate } & \multicolumn{1}{c|}{ S.E. } & \multicolumn{1}{c|}{ C.R. } & \multicolumn{1}{l|}{ P } \\
\hline SP $\leftarrow$ HRM & 0.304 & 0.078 & 3.646 & 0.000 \\
\hline CM $\leftarrow$ HRM & 0.3 & 0.112 & 3.325 & 0.000 \\
\hline SP $\leftarrow$ ISM & 0.73 & 0.151 & 5.835 & 0.000 \\
\hline $\mathbf{C M} \leftarrow \mathbf{I S M}$ & 0.54 & 0.177 & 4.888 & 0.000 \\
\hline F/FM $\leftarrow$ HRM & 0.503 & 0.079 & 4.773 & 0.000 \\
\hline F/FM $\leftarrow$ ISM & 0.44 & 0.112 & 3.794 & 0.000 \\
\hline RM $\leftarrow$ SP & 0.49 & 0.083 & 4.499 & 0.000 \\
\hline SIM $\leftarrow \mathbf{S P}$ & 0.294 & 0.097 & 3.066 & 0.002 \\
\hline RM $\leftarrow \mathbf{C M}$ & 0.43 & 0.058 & 4.229 & 0.000 \\
\hline SIM $\leftarrow \mathbf{C M}$ & 0.562 & 0.074 & 5.769 & 0.000 \\
\hline LSA $\leftarrow$ RM & 0.231 & 0.162 & 1.711 & 0.087 \\
\hline LSA $\leftarrow$ SIM & 0.223 & 0.118 & 1.714 & 0.087 \\
\hline
\end{tabular}

\section{Discussion}

Out of 14 existing hypotheses, 2 have been dismissed with all the rest adopted and 1 hypothesis added. The result of hypothesis testing is summarized in Table 8.

When it comes to human resources management, it will have positive effect on management and control of freight and security of facilities for a corporation to provide its employees with training on supply chain security. Additionally, it will have positive effect on the process related to supply chain security and capability to prevent crisis and cope with it upon occurrence. This means that human resources management is a prerequisite task in securing capabilities for facilities/freight management, security process and crisis management.

Information system management tells us that corporate capability for information system has very much effect on its capabilities for facilities/freight management, security process and crisis management. In other words, good management of information system can ensure effective activities in facilities/freight management, security process and crisis management. 
Facilities/freight management does not have direct effect on relationship with partners and sharing of logistic information but can be interpreted to have direct effect on logistics security accomplishment.

Security process is connected to relationship with partners in chain of supply and sharing of logistics information meaning that security is a prerequisite task for relationship with partners and sharing of logistics information.

Capability for management of crisis is connected to relationship with partners and sharing of information with partners, corporation and outsiders in a crisis situation meaning that securing capability for crisis management is a prerequisite task in having effective relationship with partners and sharing logistic information.

This further indicates that relationship management has more effect on logistics security accomplishment than sharing of logistic information. Just as relationship between corporations in chain of supply and sharing of information among them are important elements in management of supply chain, relationship with partners and sharing of logistic information will have positive effect on supply chain security accomplishment and raise its effectiveness.

\section{Table 8.}

Hypothesis testing

\begin{tabular}{|c|c|c|c|c|}
\hline & \multicolumn{3}{|c|}{ Hypothesis } & \\
\hline H1 & Human Resources Management & $\rightarrow$ & Facilities/freight management & Accept \\
\hline $\mathrm{H} 2$ & Human Resources Management & $\rightarrow$ & Security process & Accept \\
\hline H3 & Human Resources Management & $\rightarrow$ & Crisis management & Accept \\
\hline H4 & Information System Management & $\rightarrow$ & Facilities/freight management & Accept \\
\hline H5 & Information System Management & $\rightarrow$ & Security process & Accept \\
\hline H6 & Information System Management & $\rightarrow$ & Crisis management & Accept \\
\hline H7 & Facilities/freight management & $\rightarrow$ & Relationship Management & Reject \\
\hline H8 & Facilities/freight management & $\rightarrow$ & Sharing of logistics information & Reject \\
\hline H9 & Security process & $\rightarrow$ & Relationship Management & Accept \\
\hline H10 & Security process & $\rightarrow$ & Sharing of logistics information & Accept \\
\hline H11 & Crisis management & $\rightarrow$ & Relationship Management & Accept \\
\hline H12 & Crisis management & $\rightarrow$ & Sharing of logistics information & Accept \\
\hline H13 & Relationship Management & $\rightarrow$ & Logistics security accomplishment & Accept \\
\hline H14 & Sharing of logistics information & $\rightarrow$ & Logistics security accomplishment & Accept \\
\hline H15 & Facilities/freight management & $\rightarrow$ & Logistics security accomplishment & Accept \\
\hline
\end{tabular}




\section{Conclusion}

Examination of the relationship between supply chain security activities and supply chain security accomplishment measured from the perspective of BSC indicates the following.

Firstly, human resources management has been known to have effect on facilities/freight management, security process and capability for crisis management. Likewise, information system management has effect on facilities/freight management, security process and capability for crisis management. Although information system management has stronger effect on facilities/freight management, security process and capability for crisis management, good management of human resources and information system should precede effective activities in facilities/freight management, security process and capability for crisis management. Secondly, facilities/freight management has been found out to have no effect on relationship with partners but has direct effect on logistics security accomplishment meaning that facilities/freight management is an indispensable element in logistics security accomplishment but does not have any effect on relationship with partners and sharing of logistic information. It turned out that security process has positive effect on both relationships with partners and activities in sharing logistic information and that crisis management capability too has positive influence on relationship with partners and sharing of logistic information. This tells us that security process and crisis management capability affect corporate relationship with partners in chain of supply and sharing of logistic information and that these are the prerequisite tasks. Forth, relationship with partners and sharing of logistic information has positive effect on logistics security accomplishment and this tells us that relationship with partners should be in place and logistic information shared in the first place for accomplishment in logistics security.

Significance of this research can be summarized as follows.

Firstly, supply chain security activities from the perspective of BSC have causal relationship with supply chain security activities and have positive influence on corporate supply chain security accomplishment. Secondly, it is important to proceed, on a step by step and intensive basis, with supply chain security activities organized from the perspective of learning and growth, internal business, customer and finance according to causal relationship between respective activities.

Despite such significance, this research is not free from following restrictions. Firstly, it was difficult to objectively measure supply chain security accomplishment which can be measured only after occurrence of security related incidents. Secondly, limited number of questions contained in the questionnaire and survey targets were also restrictions. 107 
effective questions against 8 theoretical variables were far from sufficient. It will be, therefore, necessary for follow-on studies to reflect opinions from service providers and logistics companies across the industry including, of course, various manufacturers. Additionally, researches reflecting measurement indicators which can objectively measure supply chain security accomplishment need to be undertaken.

\section{Acknowledgement}

This work was supported by Jungseok Logistics Foundation Grant. 


\section{References}

Min Gyeong Gi. 2005. A study on the relationships between logistics strategy and its performance of Korean manufacturing companies from BSC perspective. $P h$. D Dissertation, Kwangwoon University.

Lee Sang Hun. 2003. Performance measure for the information system projects of e-Government with BSC. MS Thesis, KAIST.

A Erera, KH Kwek, N Goswami, C White, H Zhang. 2003. Cost of security of sea cargo transport. The Logistics Institute - Asia Pacific

Barchi Peleg-Gillai, Gauri Bhat, Leslet Sept. 2006. Innovators in Supply chain security: better security drives business value. The Manufacturing Innovation Series, available at: www.ibm.com

B.M Lewis, A.L. Erera, C.C. White III. 2002. Optimization Approaches for Efficient Container Security Operations at Transshipment Seaports. Transportation Research Record. 1822: 1-8.

CBRA-Butierrez, Hintas. 2007. Voluntary supply chain security program impacts: An empirical study with BASC member companies. World Customs Journal. vol. 2, no.1: 31-48.

C.C. White III, A.L. Erera, MWP Savelbergh. A research agenda for supply chain security and productivity. NSF Report. Atlanta, Ga., 2004

David Closs, O. Keith Helferich, Daniel Lynch, Robyn Mace, Ed McGarrell, Cheri Speier, Judy Whipple, Doug Voss, Dan French. Defending the Food Supply Chain: Participant Summary. Manuscript, Michigan State University, East Lansing, MI, 2006

H Hesse, N. Charalambous. 2004. New security measures for the international shipping community. WMU Journal of Maritime Affairs, vol. 3, no. 2: 123-138

H.H. Wills, D. S. Ortiz, Evaluating the security of the global containerized supply chain. Technical Report, RAND, 2004

J.A. Roach. 2004. Initiatives to enhance maritime security at sea. Marine Policy, vol. 28, no. 1: 41-66.

James B. Rice, Jr., Philip W. Spayd. Investing in supply chain security : Collateral Benefits. Special report from IBM Center for the Business of Government. 2005

Mike C. Farrell. 2008. Implication of Piracy on Supply-chain security. Retrieved at http://smooz.4your.net/ asisonline/files/piracy.pdf

P Barnes, R Oloruntoba. 2005. Assurance of Security in maritime supply chain: Conceptual issue of vulnerability and crisis management. Journal of International Management. vol. 11, no. 4: 519-540

$\mathrm{R}$ Banomyong. 2005. Impact of port and trade security initiatives on maritime 
supply-chain management. Maritime Policy \& Management. vol. 32, no. 1: 3-13.

Randy Mullet, Alejandra Palma, Anusha Seneviratne, Macro Rodriguez. Intermodal container security in the post 9/11 Era. Virginia Polytechnic Institute and State University. 2004.

R.S. Kaplan and D.P. Norton, 1992. The Balanced Scorecard Measures that Drive Performance. Harvard Business Review. January-February.

Susan E. Martonosi, David S. Ortiz, Henry H. Wills, The economic impacts of terrorist attacks, chap. 12. Evaluating the viability of 100 percent container inspection at America's ports. Edward Elgar Publishing Inc., 2007.

WCO, SAFE Framework of standard, 2007

Yossi Sheffi. 2003. Supply chain management under the treat of international terrorism. International Journal of Logistics Management. vol. 12, no. 2:1-11. 